Mr. PIPER has rather missed the point of my communication, which was to direct attention to the value of the Arnon technique, since this, so far as I was aware, had not until then been used in Great Britain. I exemplified this value by quoting some of my own experiments with oats. I certainly did not wish to suggest that there was anything new in producing the symptoms of grey-speck disease in water culture, and I had assumed that all those interested would be well acquainted with the work of Samuel and Piper, published some fifteen years ago, since it was this work which established the proof of the connexion between grey-speck disease and manganese deficiency.

With regard to the effect of molybdenum on the growth of oats, I would say that I have now been able to read Mr. Piper's paper which, probably owing to war conditions, had not reached me at the time of the publication of my earlier letter. There is now no doubt that molybdenum is an essential element for the growth of oats. It still remains to be proved, however, whether one or more of the other elements of Arnon's original B7 group (chromium, titanium, vanadium, tungsten, nickel and cobalt) were also responsible for at least part of the response obtained in the experiment reported in my communication.

I would like to take this opportunity of correcting an error made in my letter where $I$ included aluminium among the seven elements of the $B 7$ group; this should have been chromium. Thus for aluminium read chromium in Mr. Piper's letter in this issue.

Botany Department, E. S. TwYman.

University of Birmingham.

\section{Development of Botanical Investigations at Rothamsted}

IN an article in NATURE of July 24 entitled "Dovelopment of Botunical Investigations at Rothamsted", the following statement is made with reference to 'minor' elements and plant growth' :

"Stimulation with minute traces of elements was far more difficult to demonstrate, though some indication was obtained. Following up an accidental clue obtained in 1921, Dr. K. Warington proved conclusively that in the absence of a trace of boron, growth of broad beans was completely checked. . .."

I am not sure what constitutes an "accidental clue" in scientific investigations, but as a matter of historical interest in the progress of our knowledge about the effects produced by minute quantities of boron on the growth of broad beans, attention might be directed to the following statement made by Dr. Warington in the introduction to her classical paper published in $1923^{2}$.

"In some experiments carried out by Dr. J. Davidson at Rothamsted in 1920 in connection with the bean aphis, broad bean plants in water culture solution supplied with a small quantity of boric:acid were strikingly superior to the rest of the series; accordingly, the present investigation was undertaken in order to determine more fully the action of boric acid on the broad bean and certain other plants."

The experiments referred to formed part of a wide programme of research, which aimed at finding out by means of controlled experiments with the black aphis on broad beans "whether changes can be introduced in the sap of the growing plant, so as to affect its suitability as food for the aphids, and at the same time not adversely affect the plant"3.

Waite Agricultural Research Institute, James Davioson. University of Adelaide.

' NATURE, 152, 91 (1943).

${ }^{2}$ Warington, K., Ann. Bot., 27, 631 (1923).

${ }^{3}$ Davidson, J., Ann. Appl. Biol., 12, 494 (1925).

\section{The British Elm Flora}

The view expressed by Howard in his interesting article on the elm tree ${ }^{1}$, that there are but two species represented in the United Kingdom "with perhaps nine or more hybrids or varieties", is no longer accepted by botanists. It is true that the common or English elm and the wych elm are the most widely-spread species and both are undoubtedly native. The wych elm, the correct name for which is Ulmus glabra Huds., occurs throughout the country, but the common elm is concentrated in the south, thins out in northern England and is probably only planted in Scotland. This species is now known as $U$. procera Salisbury, the Linnean name $U$. campestris being a nomen ambiguum ${ }^{2}$. Its distribution in the country is quite natural, and so far it has been recorded from the Continent only as a planted tree; the evidence strongly favours the view that it is endemic, in spite of the misgivings of earlier writers.

The parts of England to the south and east of a line drawn from the Bristol Channel to the Humber has an unusually rich elm flora, including several species that appear to be endemic, though their status cannot be finally settled until a critical exam. ination has been made of the elms of the neighbouring parts of the Continent. The Cornish elm, $U$. stricta Lindley, is abundant in Cornwall and Devon, thins out eastward into Dorset and is represented by a variety, the Goodyear elm, var. Goodyeri Melville ${ }^{3}$, to the south of the New Forest, and by a further variety, the Wheatley or Jersey elm, var. sarniensis (Loud.) Moss, in the Channel Islands and possibly adjacent parts of France. The three varieties form a geographical series or topocline increasing in breadth of leaf from west to east4. In low-lying parts of the river valleys, from the Wash across to the Severn, is found the most distinctive and elegant of our endemic species, the Plot elm, U. Plotii Druce ${ }^{5}$. The Continental smooth-leaved elm, $U$. carpinifolia Gleditsch ( $U$. nitens Moench), is doubtfully native, but we have instead the East Anglian elm, $U$. diversifolia Melville ${ }^{6}$, having shoots with symmetrical leaves interspersed with others bearing the usual lop-sided leaves and another species with intergrading varieties extending across the Midlands and East Anglia. The latter awaits description, as does the small-leaved elm of East Anglia related to the. Plot elm.

The Dutch elm, $\times$ G. hollandica Mill. var. major (Sm.) Rehd. and the Huntingdon elm, $\times U$. hollandica var. vegeta (Loud.) Rehd., are widely planted; both are presumed to be hybrids of the wych elm with $U$. carpinifolia Gleditsch. There are numerous natural hybrids; the wych elm apparently hybridizes freely with all the other species except $U$. procera, which normally has finished flowering before the wych elm starts. It is probable that many of the hybrids are fertile, as intergrading series of hybrid forms connect the species. The intergrades are particularly numerous between U. glabra and $U$. Plotii and may be arranged in sequences on leaf shape 